\title{
RELEVANSI KOMPETENSI LULUSAN SEKOLAH MENENGAH KEJURUAN TEKNIK KOMPUTER JARINGAN DENGAN KEBUTUHAN DUNIA INDUSTRI
}

\author{
Titin Kristianingsih ${ }^{1}$, Afis Pratama ${ }^{2}$, Handini Arga Damar Rani ${ }^{3}$ \\ Universitas Ivet ${ }^{123}$ \\ Kristianingsihtitin@gmail.com
}

\begin{abstract}
ABSTRAK
Tujuan penelitian ini merupakan suatu kegiatan yang harus diketahui sebelum menentukan kegiatan penelitian. Adapun tujuan penelitian ini adalah sebagai berikut: (1) Mendeskripsikan dan menjelaskan kurikulum yang ada di Sekolah Menengah Kejuruan (SMK) Teknik Komputer Jaringan (TKJ). (2) Mendeskripsikan dan menjalaskan keahlian yang dibutuhkan dunia industri, sesuai dengan jurusan Teknik Komputer dan Jaringan (TKJ). (3) Mengetahui tingkat relevansi kompetensi lulusan Sekolah Menengah Kejuruan (SMK) Teknik Komputer Jaringan (TKJ) dengan kebutuhan dunia industri. Dalam penelitian ini penulis menggunkan penelitian kuantitatif dengan metode survey. Hasil penelitian ini adalah Nilai $56 \%$ menunjukan bahwa Struktur Kurikulum yang telah disusun oleh pemerintah termasuk dalam katagori "Relevan" dengan kompetensi yang dibutuhkan di Perusahaan Kota Blora. Taraf "Relevan" dengan kompetensi yang digunakan sebagai generalisasi terhadap presentase kebutuhan dari semua perusahaan di Kota Blora pada kompetensi TKJ yang ada di sekolah. Secara keseluruhan tingkat relevansi kompetensi SMK TKJ di Kota Blora dengan kebutuhan dunia industri dengan presentase 56\%. Ini menunjukan secara keseluruhan kompetensi yang di ajarkan di SMK TKJ Kota Blora relevan dengan dunia industri.
\end{abstract}

Kata Kunci: relevansi kompetensi, SMK, Teknik Komputer Jaringan, dunia industri.

\begin{abstract}
The purpose of this research is an activity that must be known before determining the research activity. The objectives of this research are as follows: (1) describing and explaining the curriculum in vocational high School (SMK) network computer Engineering (TKJ). (2) describing and spreading the expertise needed by the industry, according to the Department of Computer and Network Engineering (TKJ). (3) Knowing the relevance level of the competency of Vocational High School (SMK) network computer Engineering (TKJ) with the needs of the industrial world. In this research the authors use quantitative research with survey methods. The result of this research is the value of $56 \%$ indicates that the curriculum structure that has been compiled by the government is included in the category of "relevant" with the competencies needed in the company Blora City. The "relevant" level with the competency used as generalization of the percentage of the needs of all companies in Blora City on TKJ competence in schools. Overall the relevance of SMK TKJ competence in Blora City with the needs of the industry with a percentage of $56 \%$. This shows that the overall competency taught at SMK TKJ Blora City is relevant to the industry.
\end{abstract}

Keywords: the relevance of competence, SMK, computer Engineering Network, industrial world.

\section{PENDAHULUAN}

Sekolah Menengah Kejuruan (SMK) merupakan jenjang pendidikan yang dipilih sebagian besar siswa setelah lulus ke jenjang Pendidikan SMP/MTs, siswa/siswa yang memililih lanjut ke jenjang pendidikan SMK untuk mencari pekerjaan yang sesuai dengan jurusan yang mereka pilih setelah siswa/siswa lulus. Dalam jenjang pendidikan Sekolah Menengah Kejuruan (SMK) terdapat banyak kompetensi kejuruan yang ada di SMK, salah satunya kompetensi kejuruan Teknik Komputer Jaringan (TKJ). Teknik Komputer dan Jaringan (TKJ) merupakan 
salah satu paket keahlian yang ditawarkan di SMK bidang keahlian Teknologi Informasi dan Komunikasi. Paket keahlian ini mempelajari tentang software-hardware pada komputer dan jaringan, konsep jaringan, local and wide area network, serta rancang bangun server (Saputra, 2014). Pemrograman Animasi komputer dianggap sebagai kompetensi penting bagi pengembangan keterampilan pemecahan masalah selain penalaran logis (Pratama, 2018). Dengan tingginya minat siswa terhadap SMK, menjadi keharusan bagi tiap satuan pendidikan untuk meningkatkan kualitas lulusan dan merancang program terbaik agar lulusan SMK bisa menghasilkan produk berkualitas, termasuk program keahlian TKJ yang mampu berkompetisi di dunia kerja. Namun pada kenyataannya, dari program-program yang telah dilaksanakan di pendidikan, terdapat beberapa masalah yang ditemui sehingga antara satuan pendidikan dan dunia industri terjadi perbedaan. Maka penulis tertarik untuk mengangkat permasalahan tersebut sebagai proyek skripsi dengan judul "RELEVANSI KOMPETENSI LULUSAN SEKOLAH MENENGAH KEJURUAN TEKNIK KOMPUTER JARINGAN DENGAN KEBUTUHAN DUNIA INDUSTRI".

Berdasarkan uraian diatas maka rumusalan masalah yang didapat yaitu Seperti apa tingkat relevansi kompetensi lulusan SMK Teknik Komputer Jaringan (TKJ) dengan kebutuhan dunia industri?.

Adapun tujuan penelitian ini adalah sebagai berikut: (1) Mendeskripsikan dan menjelaskan kurikulum yang ada di Sekolah Menengah Kejuruan (SMK) Teknik Komputer Jaringan (TKJ). (2) Mendeskripsikan dan menjelaskan keahlian yang dibutuhkan dunia industri, sesuai dengan jurusan Teknik Komputer dan Jaringan (TKJ). (3) Mengetahui tingkat relevansi kompetensi lulusan Sekolah Menengah Kejuruan (SMK) Teknik Komputer Jaringan (TKJ) dengan kebutuhan dunia industri.
Adapun manfaat dari penelitian yang dibuat nantinya bisa bermanfaat bagi sekolahan, perusahaan, siswa,dan bagi peneliti juga.

\section{METODE PENELITIAN}

Penelitian ini menggunakan penelitian kuantitatif dengan metode survey yang digunakan untuk mendapatkan data dari tempat tertentu yang alamiah (bukan buatan), tetapi peneliti melakukan perlakuan dalam pengumpulan data, misalnya dengan mengedarkan kuisioner, test, wawancara, tersetruktur dan sebagainya (Sugiyono, 2018: 6). Pengambilan data yang dilakukan menggunakan kuisioner tidak langsung ke lapangan atau melalui sosial media dan google formulir.

Langkah-langkah penelitian yang dilakukan adalah sebagai berikut:

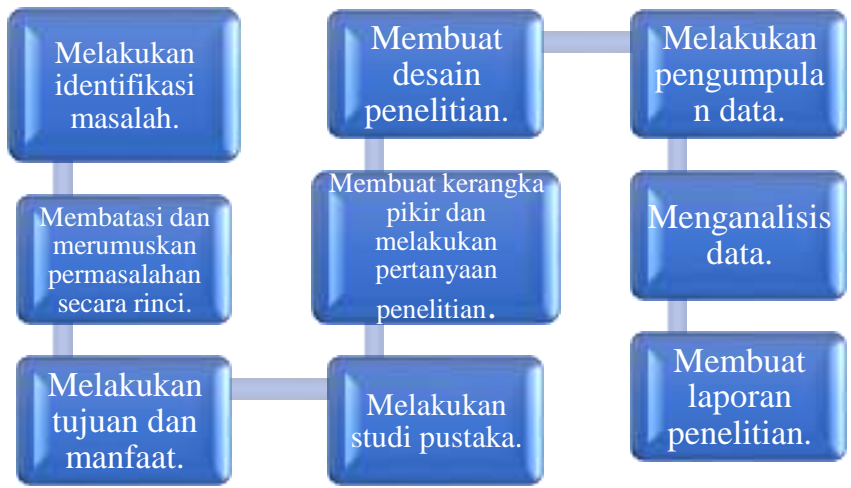

Gambar 1. Langkah-langkah penelitian yang dilakukan.

Sejalan dengan pendapat Sugiyono (2018: 81) yang mengatakan bahwa, "Sampel adalah bagian dari jumlah dan karakteristik yang dimiliki oleh populasi". Jumlah sampel akan sangat bergantung pada berapa banyak jumlah populasi. Dari penelitian ini jumlah sampel yang digunakan dalam penelitian ini ada 30 siswa dari kelas X, 30 siswa dari kelas XI dan 5 Guru produktif. Untuk menentukan jumlah sampel dalam penelitian ini menggunakan rumus slovin, sebagai berikut:

$$
\mathrm{n}=\mathrm{N}
$$




$$
1+\mathrm{Ne}^{2}
$$

Keterangan:

$\mathrm{n}$ : Jumlah sampel

$\mathrm{N}$ : Jumlah populasi

e : Persen kelonggaran ketidak telitian kesalahan pengambilan sampel yang dapat ditolelir (e dalam penelitian ini ditentukan sebesar 5\%).

\section{SUMBER DATA DAN SUBJEK PENELITIAN}

Setiap kegiatan penelitian senantiasa memerlukan sumber data. Data yang diperoleh dari lapangan untuk kemudian dianalisis dan digunakan untuk menjawab masalah yang diteliti atau untuk menjawab hipotesis dan mengambil kesimpulan. Sugiyono (2018: 80) menyatakan bahwa : "populasi adalah wilayah generalisasi yang terdiri atas; objek/subjek yang mempunyai kualitas dan karakteristik tertentu yang ditetapkan oleh peneliti untuk dipelajari dan kemudian ditarik kesimpulannya". Sesuai dengan permasalahan penelitian, maka yang menjadi populasi pada penelitian ini adalah siswa TKJ, guru produktif yang bernama Heri Prayitno dan Ninik Siswanti dari SMK Muhammadiyah Randublatung, Siti Fadilah dan Nyipta Nur Indah dari SMK Al Mustawa, Anies Sholikhah dan Fitria Chomari dari SMK NU Kunduran dan pegawai lapangan maupun non lapangan yang bekerja di sebuah perusahaan jaringan yang ada di Kabupaten Blora

Tabel 1. Jumlah sampel SMK.

\begin{tabular}{llll}
\hline No & Kelas & $\begin{array}{l}\text { Jumlah } \\
\text { populasi }\end{array}$ & $\begin{array}{l}\text { Jumlah } \\
\text { sampel }\end{array}$ \\
\hline 1 & X & 30 & 30 \\
\hline 2 & XI & 30 & 30 \\
\hline 3 & $\begin{array}{l}\text { Guru } \\
\text { Produktif }\end{array}$ & 5 & 5 \\
\hline & & 65 & 65
\end{tabular}

Jumlah sampel adalah sebanyak 60 siswa siswi kelas X dan XI yang diambil dari 60 siswa siswi kelas X dan XI dan 5 responden Guru Produktif.

TEKNIK PENGUMPULAN DATA
Teknik pengumpulan data penelitian dilakukan dengan metode survai. Jenis teknik survai yang dilakukan adalah survai via phone/telephone dimana peneliti berada di luar narasumber/pemberi data yang diamati dan tidak ikut dalam kegiatankegiatan yang mereka lakukan. Metode survai ini yang digunakan untuk memperoleh data tentang kompetensi TKJ adalah kuesioner. Dan pertanyaan bersifat kuesioner pilihan ganda yang nantinya peneliti memberi pertanyaan kepada narasumber jika pertanyaan itu sesuai dengan yang dimaksud maka hasilnya berupa silang ( $\mathrm{X}$ ).

Analisis data dilakukan terhadap data yang diperoleh dari data kuesioner. Dari data yang telah diperoleh dilakukan rekapitulasi data dan analisis sebagai berikut:

1. Kompetensi yang diajarkan di SMKTKJ Blora.

2. Kompetensi yang dibutuhkan oleh dunia kerja

3. Kompetensi TKJ yang diajarkan di SMK tetapi tidak dibutuhkan di Dunia kerja.

4. Kompetensi TKJ yang dibutuhkan di dunia kerja tetapi tidak diajarkan di SMK.

5. Tingkat relevansi kompetensi keahlian TKJ yang diajarkan di SMK dengan kompetensi yang dibutuhkan di dunia kerja.

Dari hasil rekapitulasi, dilakukan perhitungan relevansi menggunakan Arikunto (2010) yang diajarkan di SMKTKJ dengan kompetensi yang dibutuhkan di dunia kerja dengan rumus perhitungan presentase adalah sebagai berikut:

$$
\mathrm{Ka}=\frac{A a}{B a} X 100 \%
$$

Keterangan:

$\mathrm{Ka}=$ persentase tingkat relevansi kompetensi TKJ.

$\mathrm{Aa}=$ jumlah skor riil kompetensi yang sesuai dengan industri.

$\mathrm{Ba}=$ skor maksimal kompetensi. 
Setelah diperoleh hasil perhitungan persentase, maka dilakukan perbandingan hasil persentase yang diperoleh dengan pembagian tingkat relevansi yang telah ditetapkan. Dalam hal ini, pembagian tingkat relevansi yang digunakan mengacu pada indikator kategori relevansi di bawah ini (Suharsimi Arikunto, 2010).

Tabel 2.Indikator kategori relevansi.

\begin{tabular}{ll}
\hline $\begin{array}{l}\text { Taraf } \\
\text { Presentase }\end{array}$ & Kategori \\
\hline $76 \%-100 \%$ & SANGAT \\
$56 \%-75 \%$ & RELEVAN \\
$40 \%-55 \%$ & RELEVAN \\
$<40 \%$ & KURANG \\
& RELEVAN \\
& TIDAK \\
& RELEVAN \\
\hline
\end{tabular}

\section{HASIL DAN PEMBAHASAN}

Uji Analisis

1. Uji Validitas

Uji validitas adalah prosedur untuk memastikan valid atau tidaknya variabel penelitian. Data dikatakan valid jika

\section{Uji Reliabilitas}

Uji reliabilitas adalah prosedur untuk mengukur suatu kuisioner yang merupakan indikator dari variabel. Data dikatakan reliabel jika nilai Cronbach's Alpha $\geq 0,60$. Berikut hasil uji reliabilitas.

3. Uji Validitas untuk Kelas XI

Tabel 5. Hasil uji validitas kelas XI

\begin{tabular}{l|l|l|l}
\hline $\begin{array}{l}\text { No. } \\
\text { Buti } \\
\mathrm{r}\end{array}$ & $\begin{array}{l}\mathrm{R} \\
\text { hitun } \\
\mathrm{g}\end{array}$ & $\begin{array}{l}\text { Keteranga } \\
\mathrm{n}\end{array}$ & $\begin{array}{l}\text { Interpretas } \\
\mathrm{i}\end{array}$ \\
\hline 1 & 0,882 & $>0,3610$ & Valid \\
2 & 0,607 & $>0,3610$ & Valid \\
3 & 0,808 & $>0,3610$ & Valid \\
4 & 0,682 & $>0,3610$ & Valid \\
5 & 0,808 & $>0,3610$ & Valid \\
6 & 0,773 & $>0,3610$ & Valid \\
7 & 0,665 & $>0,3610$ & Valid \\
8 & 0,882 & $>0,3610$ & Valid \\
9 & 0,814 & $>0,3610$ & Valid
\end{tabular}

signifikansi data $<0,05$ atau $\mathrm{R}$ hitung $>\mathrm{R}$ tabel.

a. Uji Validitas untuk Kelas X

Tabel 3. Pengujian validitas kuisioner kelas X

\begin{tabular}{l|l|l|l}
\hline $\begin{array}{l}\text { No. } \\
\text { Buti } \\
\mathrm{r}\end{array}$ & $\begin{array}{l}\text { R } \\
\text { hitun } \\
\mathrm{g}\end{array}$ & $\begin{array}{l}\text { Keteranga } \\
\mathrm{n}\end{array}$ & $\begin{array}{l}\text { Interpretas } \\
\mathrm{i}\end{array}$ \\
\hline 1 & 0,787 & $>0,3610$ & Valid \\
2 & 0,704 & $>0,3610$ & Valid \\
3 & 0,560 & $>0,3610$ & Valid \\
4 & 0,570 & $>0,3610$ & Valid \\
5 & 0,790 & $>0,3610$ & Valid \\
6 & 0,523 & $>0,3610$ & Valid \\
7 & 0,745 & $>0,3610$ & Valid \\
8 & 0,600 & $>0,3610$ & Valid \\
9 & 0,757 & $>0,3610$ & Valid \\
10 & 0,757 & $>0,3610$ & Valid \\
\hline
\end{tabular}

Data dikatakan valid jika signifikansi data < 0,05, atau $\mathrm{R}$ hitung $>\mathrm{R}$ tabel. Berdasarkan Tabel diatas menunjukkan bahwa semua data dikatakan valid, karena tingkat signifikansi $<0,05$ dan $\mathrm{R}$ hitung $>\mathrm{R}$ tabel, dimana nilai $\mathrm{R}$ tabel sebesar 0,3610.

Tabel 4. Hasil uji reliabelitas kelas X

Reliability Statistics

\begin{tabular}{l|l}
\hline $\begin{array}{l}\text { Cronbach's } \\
\text { Alpha }\end{array}$ & N of Items \\
\hline .870 & 10 \\
\hline
\end{tabular}

\begin{tabular}{cccc}
10 & 0,814 & $>0,3610$ & Valid \\
11 & 0,756 & $>0,3610$ & Valid \\
12 & 0,587 & $>0,3610$ & Valid \\
13 & 0,644 & $>0,3610$ & Valid \\
14 & 0,587 & $>0,3610$ & Valid \\
15 & 0,644 & $>0,3610$ & Valid \\
16 & 0,551 & $>0,3610$ & Valid \\
17 & 0,882 & $>0,3610$ & Valid \\
18 & 0,763 & $>0,3610$ & Valid \\
19 & 0,882 & $>0,3610$ & Valid \\
20 & 0,763 & $>0,3610$ & Valid \\
\hline
\end{tabular}


Data dikatakan valid jika signifikansi data $<0,05$, atau $\mathrm{R}$ hitung $>\mathrm{R}$ tabel.

Berdasarkan Tabel diatas menunjukkan bahwa semua data dikatakan valid, karena tingkat signifikansi $<0,05$ dan $\mathrm{R}$ hitung $>$ $\mathrm{R}$ tabel, dimana nilai $\mathrm{R}$ tabel sebesar 0,3610 .

\section{Uji Reliabilitas}

Uji reliabilitas adalah prosedur untuk mengukur suatu kuisioner yang merupakan indikator dari variabel. Data dikatakan reliabel jika nilai Cronbach's Alpha $\geq 0,60$. Berikut hasil uji reliabilitas.

Tabel 6. Hasil uji reliabelitas kelas XI Reliability Statistics

\begin{tabular}{l|l}
\hline $\begin{array}{l}\text { Cronbach's } \\
\text { Alpha }\end{array}$ & N of Items \\
\hline .956 & 20 \\
\hline
\end{tabular}

5. Uji Validitas untuk Guru Produktif

Berikut hasil uji validitas untuk Guru Produktif :

Tabel 7. Uji validitas Guru Produktif

\begin{tabular}{cccc}
\hline $\begin{array}{c}\text { No. } \\
\text { Butir }\end{array}$ & $\begin{array}{c}\mathrm{R} \\
\text { hitung }\end{array}$ & Keterangan & Interpretasi \\
\hline 1 & 1,000 & $>0,3610$ & Valid \\
2 & 1,000 & $>0,3610$ & Valid \\
3 & 1,000 & $>0,3610$ & Valid \\
4 & 1,000 & $>0,3610$ & Valid \\
5 & 1,000 & $>0,3610$ & Valid \\
6 & 1,000 & $>0,3610$ & Valid \\
7 & 1,000 & $>0,3610$ & Valid \\
8 & 1,000 & $>0,3610$ & Valid \\
9 & 1,000 & $>0,3610$ & Valid \\
10 & 1,000 & $>0,3610$ & Valid \\
11 & 1,000 & $>0,3610$ & Valid \\
12 & 1,000 & $>0,3610$ & Valid \\
13 & 1,000 & $>0,3610$ & Valid \\
14 & 1,000 & $>0,3610$ & Valid \\
15 & 1,000 & $>0,3610$ & Valid \\
16 & 1,000 & $>0,3610$ & Valid \\
17 & 1,000 & $>0,3610$ & Valid \\
18 & 1,000 & $>0,3610$ & V \\
19 & 1,000 & $>0,3610$ & V \\
20 & 1,000 & $>0,3610$ & Valid
\end{tabular}

\begin{tabular}{llll}
21 & 1,000 & $>0,3610$ & Valid \\
22 & 1,000 & $>0,3610$ & Valid \\
23 & 1,000 & $>0,3610$ & Valid \\
24 & 1,000 & $>0,3610$ & Valid \\
25 & 1,000 & $>0,3610$ & Valid \\
26 & 1,000 & $>0,3610$ & Valid \\
27 & 1,000 & $>0,3610$ & Valid \\
28 & 1,000 & $>0,3610$ & Valid \\
29 & 1,000 & $>0,3610$ & Valid \\
30 & 1,000 & $>0,3610$ & Valid \\
\hline
\end{tabular}

Data dikatakan valid jika signifikansi data < 0,05, atau $\mathrm{R}$ hitung $>\mathrm{R}$ tabel. Berdasarkan Tabel diatas menunjukkan bahwa semua data dikatakan valid, karena tingkat signifikansi $<0,05$ dan $\mathrm{R}$ hitung $>\mathrm{R}$ tabel, dimana nilai $\mathrm{R}$ tabel sebesar 0,3610 .

6. Uji Reliabilitas

Uji reliabilitas adalah prosedur untuk mengukur suatu kuisioner yang merupakan indikator dari variabel. Data dikatakan reliabel jika nilai Cronbach's Alpha $\geq 0,60$. Berikut hasil uji reliabilitas.

Tabel 8. Hasil uji reliabelitas Guru produktif

\section{Reliability Statistics}

\begin{tabular}{l|l}
\hline $\begin{array}{l}\text { Cronbach's } \\
\text { Alpha }\end{array}$ & N of Items \\
\hline, 970 & 30 \\
\hline
\end{tabular}

Pengambilan data di SMK dilakukan dengan mendatangi langsung Kepala Jurusan TKJ yang bersangkutan. Alasan peneliti memilih langsung Kepala Jurusan TKJ karena peneliti mengganggap lebih memahami konteks kompetensi secara keseluruhan, hal ini mata pelajaran yang diajarkan dijenjang kelas X, XI, XII dan juga Kepala Jurusan TKJ lebih banyak mengerti banyak mengenai pelaksanaan prakerin siswa di dunia industri.

Dalam penelitian ke SMK peneliti melakukan pengambilan data ke 2 Guru Produktif TKJ dan 30 siswa-siswi kelas X, XI, XII, masing-masing kelas diambil 10 swa-siswi dan pengambilan data ini eneliti mengumpulkan data dari 3 SMK yang ada di Kota Blora. 
Dari data yang didapat di tiga sekolah, kriteria yang menjadi bahan pertimbangan dalam pemilihan tempat secara keseluruhan adalah sebagai berikut:

1. Sesuai dengan kompetensi keahlian yang diajarkan di sekolah.

2. Banyak bergerak di bidang hardware komputer jaringan.

3. Tempat prakerin bersedia menjalin kerjasama dengan sekolah.

4. Memiliki bidang usaha skala menengah ke atas yang relevan sesuai dengan kompetensi SMK TKJ.

5. Merupakan perusahaan yang memiliki klien/pelanggan dengan jumlah besar dan ramai dikunjungi.

6. Memiliki kepedulian dengan dunia pendidikan, khususnya SMK TKJ.

7. Kondisi tempat kerja dan peralatan yang memadai.

Selain ditinjau dari pihak SMK, setiap perusahaan juga perlu mengetahui kompetensi-kompetensi yang telah dimiliki oleh siswa-siswa SMK TKJ sebelum diterjunkan ke lapangan/industri.

Adapun juga dapat dilihat daftar hasil pengambilan data di seluruh Perusahaan yang sudah diteliti, sebagai berikut:

Tabel 9. Kompetensi yang dibutuhkan oleh perusahaan Star Komputer.

\begin{tabular}{|c|c|c|}
\hline No & Mata Pelajaran & Dibutuhkan \\
\hline 1 & Simulasi Digital & 1 \\
\hline 2 & Sistem Komputer & 1 \\
\hline 3 & $\begin{array}{l}\text { Komputer dan } \\
\text { Jaringan }\end{array}$ & 1 \\
\hline 4 & $\begin{array}{l}\text { Pemrograman } \\
\text { Dasar }\end{array}$ & 0 \\
\hline 5 & $\begin{array}{l}\text { Dasar } \\
\text { Grafis }\end{array}$ & 0 \\
\hline 6 & $\begin{array}{l}\text { Teknologi Jaringan } \\
\text { Berbasis WAN }\end{array}$ & 0 \\
\hline 7 & $\begin{array}{l}\text { Administrasi } \\
\text { Infrastruktur } \\
\text { Jaringan }\end{array}$ & 0 \\
\hline 8 & $\begin{array}{l}\text { Administrasi } \\
\text { Sistem Jaringan }\end{array}$ & 0 \\
\hline 9 & $\begin{array}{l}\text { Teknologi Layanan } \\
\text { Jaringan }\end{array}$ & 0 \\
\hline
\end{tabular}

10 Produk Kreatif dan Kewirausahaan

Hasil pengumpulan data dari perusahaan yang sudah diteliti, jika perolehan skor 0 maka kompetensi tidak dibutuhkan oleh perusahaan tersebut, jika skor 1 maka kompetensi dibutuhkan oleh perusahaan tersebut.

Tabel 10. Kompetensi yang dibutuhkan oleh perusahaan Smart Komputer.

\begin{tabular}{clc}
\hline No & \multicolumn{1}{c}{ Mata Pelajaran } & Dibutuhkan \\
\hline 1 & Simulasi Digital & 1 \\
2 & Sistem Komputer & 1 \\
3 & Komputer dan Jaringan & 1 \\
4 & Pemrograman Dasar & 1 \\
5 & Dasar Desain Grafis & 0 \\
6 & Teknologi Jaringan Berbasis & 0 \\
& WAN & 1 \\
7 & Administrasi Infrastruktur & \\
& Jaringan & 1 \\
8 & Administrasi Sistem Jaringan & 1 \\
9 & Teknologi Layanan Jaringan & 1 \\
10 & Produk Kreatif dan & \\
& Kewirausahaan & \\
\hline
\end{tabular}

Hasil pengumpulan data dari perusahaan yang sudah diteliti, jika perolehan skor 0 maka kompetensi tidak dibutuhkan oleh perusahaan tersebut, jika skor 1 maka kompetensi dibutuhkan oleh perusahaan tersebut.

Tabel 11. Kompetensi yang dibutuhkan di perusahaan Kayla Komputer.

\begin{tabular}{clc}
\hline No & \multicolumn{1}{c}{ Mata Pelajaran } & Dibutuhkan \\
\hline 1 & Simulasi Digital & 1 \\
2 & Sistem Komputer & 1 \\
3 & Komputer dan Jaringan & 0 \\
4 & Pemrograman Dasar & 0 \\
5 & Dasar Desain Grafis & 1 \\
6 & Teknologi Jaringan Berbasis & 0 \\
& WAN & \\
7 & Administrasi Infrastruktur & 0 \\
& Jaringan & 0 \\
8 & Administrasi Sistem Jaringan & 0 \\
9 & Teknologi Layanan Jaringan & 0 \\
10 & Produk Kreatif dan & 0 \\
& Kewirausahaan & \\
\hline
\end{tabular}


Hasil pengumpulan data dari perusahaan yang sudah diteliti, jika perolehan skor 0 maka kompetensi tidak dibutuhkan oleh perusahaan tersebut, jika skor 1 maka kompetensi dibutuhkan oleh perusahaan tersebut.

Tabel 12. Kompetensi yang dibutuhkan di perusahaan Creative Komputer

\begin{tabular}{clc}
\hline No & \multicolumn{1}{c}{ Mata Pelajaran } & Dibutuhkan \\
1 & Simulasi Digital & 1 \\
2 & Sistem Komputer & 1 \\
3 & Komputer dan Jaringan & 1 \\
4 & Pemrograman Dasar & 1 \\
5 & Dasar Desain Grafis & 1 \\
6 & Teknologi Jaringan Berbasis & 0 \\
& WAN & 0 \\
7 & Administrasi Infrastruktur & \\
& Jaringan & 0 \\
8 & Administrasi Sistem Jaringan & 0 \\
9 & Teknologi Layanan Jaringan & 0 \\
10 & Produk Kreatif dan & 0 \\
& Kewirausahaan & \\
\hline
\end{tabular}

Hasil pengumpulan data dari perusahaan yang sudah diteliti, jika perolehan skor 0 maka kompetensi tidak dibutuhkan oleh perusahaan tersebut, jika skor 1 maka kompetensi dibutuhkan oleh perusahaan tersebut.

Tabel 13. Kompetensi yang dibutuhkan di perusahaan Plaza Telkom Cepu

\begin{tabular}{|c|c|c|}
\hline No & Mata Pelajaran & Dibutuhkan \\
\hline 1 & Simulasi Digital & 1 \\
\hline 2 & Sistem Kompute $r$ & 0 \\
\hline 3 & Komputer dan Jaringan & 1 \\
\hline 4 & Pemrograman Dasar & 1 \\
\hline 5 & Dasar Desain Grafis & 1 \\
\hline 6 & $\begin{array}{l}\text { Teknologi Jaringan } \\
\text { Berbasis WAN }\end{array}$ & 1 \\
\hline 7 & $\begin{array}{l}\text { Administrasi Infrastruktur } \\
\text { Jaringan }\end{array}$ & 1 \\
\hline 8 & $\begin{array}{l}\text { Administrasi Sistem } \\
\text { Jaringan }\end{array}$ & 1 \\
\hline 9 & $\begin{array}{l}\text { Teknologi Layanan } \\
\text { Jaringan }\end{array}$ & 1 \\
\hline 10 & $\begin{array}{l}\text { Produk Kreatif dan } \\
\text { Kewirausahaan }\end{array}$ & 1 \\
\hline
\end{tabular}

Secara keseluruhan dari data yang telah diperoleh peneliti, kompetensi yang tidak diajarkan di SMK tetapi dibutuhkan di dunia industri yaitu seperti pemrograman visual, desain web. Yang nantinya kompetensi ini banyak dibutuhkan di perusahaan yang besar seperti Telkom.

Relevansi rat-rata $56 \%$ ini dari pengumpulan data perusahaan yang mempunyai kriteria kompetensi yang berbeda-beda dan sesuai dengan kebutuhan perusahaan itu sendiri

Dari perhitungan data tersebut didapat bahwa nilai rata-rata presentase dari semua mata pelajaran yang di ajarkan di SMK TKJ dengan yang dibutuhkan oleh dunia industri adalah 56. Angka presentase sesuai dari tiap perusahaan didapat dari perbandingan antara jumlah kompetensi yang dibutuhkan di perusahaan tersebut terhadap nilai ideal kompetensi keahlian yang diajarkan di SMK TKJ. Namun dalam hal ini masih banyak peserta didik yang belum menguasai keahlian yang diajarkan di SMK karena banyak peserta didik yang menerima pembelajaran teori/akademik saja namun kurang dalam pemelajaran praktikum, sehingga banyak peserta didik yang tidak bisa diterima di dunia industri karena tidak memahami keahlian tertentu di SMK TKJ dan lebih memilih bekerja diluar kompetensinya, hal ini sangat disayangkan karena kompetensi yang diajarkan di SMK relavan dengan kompetensi yang dibutuhkan di dunia industri.

Nilai 56\% menunjukan bahwa Struktur Kurikulum yang telah disusun oleh pemerintah termasuk dalam katagori "Relevan" dengan kompetensi yang dibutuhkan di Perusahaan Kota Blora.

\section{SIMPULAN}

Dari data pengumpulan yang telah dilakukan peneliti dapat disimpulkan bahwa tingkat relevansi SMK TKJ dengan kebutuhan dunia industry ada 56\% yang ttermasuk "Relevan". Dan dari data-data yang telah diperoleh yang lebih banyak kompetensi SMK yang sesuai dengan kebutuhan dunia industri di perusahaan 
Smart Komputer dan Telkom yang berada di Kota Blora.

\section{SARAN}

1. Relevansi kompetensi keahlian TKJ yang harus dilakukan ceranya kontinyu agar kurikulum SMK tidak tertinggal dengan perkembangan industri.

2. Hasil penelitian ini dapat menjadi acuan bagi SMK TKJ di Kota Blora dalam proses pembelajaran kompetensi agar lebih sesuai dan relevan terhadap kompetensi yang dibutuhkan oleh dunia kerja.

3. Di sekolah harus memperbanyak praktikum agar peserta didik dapat menerapkan pembelajaran yang di dapatkan dan lebih siap jika harus prakerin.

4. Pihak sekolah harus lebih mengedepankan keahlian dibandingkan akademiknya, dikarenakan kejuruan dan lebih banayak kompetensi keahliannya dibandingkan dengan kompetensi akademiknya.

DAFTAR PUSTAKA

Saputra, Wahyu Andi. 2014. Relevansi Kurikulum Kompetensi Keahlian Teknik Komputer Dan Jaringan SMK Dengan Dunia Kerja Di Kota Yogyakarta. Jurnal penelitian.

Sugiyono. 2018. Metode Penelitian Kuantitatif, Kualitatif dan $R \& D$. Bandung:Alfabeta.

Arikunto, Suharsimi. 2010. Prosedur Penelitian: Suatu Pendekatan Praktek. Jakarta: Rineka Cipta.

Pratama, A. (2018). Pengaruh Pengajaran Pemrogaman Animasi melalui Aplikasi Scratch pada Kemampuan Pemecahan Masalah. Joined Journal (Journal Of Informatics Education), 1(1), 24-31.

doi:10.31331/joined.v1i1.613. 